\title{
ESTUDO DE CASO DA GESTÃO DE ESTOQUE DE UMA CLÍNICA DE ESTÉTICA
}

\author{
STOCK MANAGEMENT CASE STUDY OF AN AESTHETICS CLINIC
}

Recebido: 28/10/2019-Aprovado: 22/12/2019 - Publicado:02/01/2020

Processo de Avaliação: Double Blind Review

\author{
Fernanda Cruz de Almeida \\ https://orcid.org/0000-0002-4334-9726 \\ Fatec Osasco- Prefeito Hirant Sanazar \\ fernanda.almeida3@fatec.sp.gov.br \\ Andressa da Silva Martins \\ https://orcid.org/0000-0003-3052-2494 \\ Fatec Osasco- Prefeito Hirant Sanazar \\ andressa.martins3@fatec.sp.gov.br \\ Patrícia Santos de Arruda \\ https://orcid.org/0000-0003-2302-4577 \\ Fatec Osasco- Prefeito Hirant Sanazar \\ patricia.arruda@fatec.sp.gov.br \\ Antonio Carlos Santos de Arruda \\ https://orcid.org/0000-0002-5031-2825 \\ Fatec Osasco- Prefeito Hirant Sanazar \\ antonio.arruda@fatec.sp.gov.br
}

RESUMO: Este artigo apresenta um estudo de caso sobre a gestão de estoque de uma clínica de estética, no qual há uma má administração de reposição, afetando diretamente o cliente. Contudo, foi formulado um instrumento de pesquisa para o responsável da atividade de estoque na empresa, conforme o referencial teórico consultado, para obter informações que estejam causando essa falha na gestão. Entretanto, após a validação das respostas, é notável que existe uma falta de conhecimento sobre o processo de gerenciamento de estoque e importância nessa área. Foram apresentadas técnicas de administração para a resolução desse problema, e, também, melhorias na visualização de como isso é possível afetar a imagem da empresa.

Palavras-chave: gestão de estoque; clínica estética; arranjo físico.

REMIPE- Revista de Micro e Pequenas Empresas e Empreendedorismo da Fatec Osasco 
ABSTRACT: This article presents a case study about stock management of an aesthetic clinic, where there is a poor replacement administration that affects directly on clients. Therefore, was formulated an instrument of research to the responsible of stock area on company, according to the theoretical framework used, to get information that probably is causing trouble on management. However, after validation of responses is clearly observed that it does not exist knowledge about a stock management process and how much it is important. It was showed administration techniques to solve the problem, and ways of improvement to facilitate to see how is possible to damage the image of the company.

Keywords: Stock management; aesthetic clinic; physical arrangement.

\section{INTRODUÇÃO}

Controle de materiais é uma área de relevância para a empresa, no qual se sua política for mal elaborada ou executada, pode acarretar problemas à organização. Em concordância com POZO (2008, p. 39), a importância da correta administração de materiais pode ser mais facilmente percebida quando os bens necessários não estão disponíveis no momento exato e correto para atender às necessidades de mercado. $\mathrm{O}$ termo controle de estoques dentro da logística, em harmonia com Pozo (2008, p. 38), é em função da necessidade de estipular os diversos níveis de materiais e produtos que a organização deve manter dentro de parâmetros econômicos.

Este estudo de caso se baseará em uma clínica prestadora de serviços estéticos de pequeno porte, no qual há a realização de procedimentos estéticos faciais e corporais, além de haver serviços médicos em questão de emagrecimento, preenchimentos e processos de aplicações de toxina botulínica. Para a elaboração deste estudo de caso, o estoque que será estudado será o de materiais descartáveis do estabelecimento, no qual os materiais que compõem o estoque de descartáveis são: papel interfolha, abaixador de língua, agulhas, seringas, máscara de procedimento, luvas de látex, touca descartável, lençol descartável e equipos de carboxiterapia.

Havendo a necessidade de um método que possa supervisionar o ponto de reposição e o de pedido de mercadorias para que não haja falta de mercadorias, após a identificação da 
demanda de mercado e o giro de estoque dos materiais citados. Dessa forma, foi gerada a seguinte pergunta norteadora: Como uma melhor gestão de materiais poderá reduzir a falta de mercadorias e impactar nos custos referentes ao estoque na empresa pesquisada?

Ao observar lacunas no objeto estudado, referentes à problemática já citada, notouse a viabilidade de elaborar um estudo de caso, com ênfase em ferramentas que possam auxiliar na gerência de produtos descartáveis. Sendo nesse contexto, este projeto justifica-se a fim de demonstrações gráficas de metodologias como a curva $\mathrm{ABC}$ e o dente de serra, com finalidade de facilitar a visualização dos níveis de estoque e fazer com que o sistema de administração de materiais seja eficaz.

Este trabalho tem como objetivo demonstrar que, a partir da melhor gestão de materiais por meio de ferramentas, o quão a administração correta pode impactar no custo de estoque da empresa, e fazendo que não haja falta de produtos, com o intuito de propor modelos que possam melhorar ou solucionar a atual gestão de materiais junto ao seu custo e, também, identificar possíveis erros de estoque, a partir de informações fornecidas pelo gestor da empresa.

\section{REFERENCIAL TEÓRICO}

\subsection{MERCADO DA ESTÉTICA}

De acordo com um levantamento realizado pela Associação Brasileira da Indústria de Higiene Pessoal, Perfumaria e Cosméticos (ABIHPEC), junto ao Instituto FSB Pesquisa, o Brasil é o terceiro país que tem o maior mercado consumidor em relação a produtos e equipamentos de beleza e estética. O país perde apenas para os Estados Unidos que têm uma porcentagem de $16,5 \%$, e para a China que tem $10,3 \%$ de todo o consumo mundial, em concordância com Dino (2018).

$\mathrm{Na}$ contramão do crescimento do Brasil, que segue se recuperando lentamente, o mercado de estética se destaca como um dos mais promissores do país, segundo Dino (2019), as perspectivas são as melhores diante de dados recém-divulgados pela Associação Brasileira da Indústria de Higiene Pessoal, Perfumaria e Cosméticos (ABIHPEC), que mostra que nos últimos cinco anos, o mercado de estética cresceu 567\% no Brasil, passando de 72 mil para mais de 480 mil profissionais. Ainda, segundo a associação que representa o 
setor, as perspectivas de crescimento para 2019 são de $1,5 \%$ a 2\%, em comparação ao ano passado, quando o setor movimentou $\mathrm{R} \$ 47,5$ bilhões.

“Em todas as épocas, a busca por salões e clínicas de estética é grande, principalmente no outono, estação com temperaturas amenas e ideal para reparar e proteger os cabelos dos danos pós-verão e prepará-los para o inverno, a estação mais fria do ano", (PITTA, 2019). Ainda de acordo Dino (2019), levando em conta a informação de que a mulher brasileira gasta anualmente 11 vezes mais com beleza do que as mulheres inglesas, e o fato de que os homens também buscam esses serviços cada vez em maior número, é preciso acompanhar as tendências e se reinventar para oferecer serviços e produtos que atendam às expectativas do público consumidor, cada vez mais exigente.

\subsection{GESTÃO DE ESTOQUES}

A administração de materiais passou a ser reconhecida, em concordância com Costenaro, Cassel e Oliveira (2016), como uma das mais importantes operações de indústrias e comércios, promovendo grande impacto no desempenho global das empresas. O característico balanço entre o custo de excesso de estoques e de sua falta e, consequente não atendimento à demanda, é o tema central das políticas de gerência de estoques.

Os estoques, em harmonia com Gitman (1997), são ativos circulantes necessários que possibilitam o funcionamento dos processos de produção e vendas com um mínimo de distúrbio e, como as duplicatas a receber, representam um investimento significativo por parte da maioria das organizações, além de, segundo Santos e Rodrigues (2006), a sua utilização de maneira correta é de extrema importância pois possibilita um melhor nível de atendimento ao cliente e melhora a competitividade da empresa em relação aos concorrentes.

A gestão dos estoques, segundo Biazzi e Gianesi (2011), consiste em operar sobre o processo de suprimento, já que a precária ação comumente pode ser feita sobre o processo de demanda e, essa atuação se traduz pela decisão de o que suprir, em que quantidade e em que momento. A administração de materiais procura equilibrar os interesses operacionais e financeiros, em concordância com Araújo e Machado (2007, p.52), sendo operacionais, por tentar impedir que a produção não pare devido à falta de um item no estoque ou um cliente não seja atendido por a companhia não disponibilizar sua necessidade naquele momento. Já 
REMIPE

os financeiros, por buscar evitar o empate de capital em itens que poderão demorar muito tempo para serem convertidos em caixa.

\subsection{TÉCNICAS DE ADMINISTRAÇÃO DE ESTOQUES}

As atuais técnicas de administração de estoques têm sido desenvolvidas, ainda em harmonia com Araújo e Machado (2007), com o intuito de reduzir ao mínimo o investimento nesse ativo. As principais técnicas encontradas na literatura são: Sistema ABC, Just in Time (JIT), Gráfico Dente de Serra e Material Requirement Planning (MRP).

O gráfico dente de serra "é uma das maneiras de se apresentar a evolução do estoque em uma empresa por um gráfico, podemos dizer que existem dois períodos distintos: período de consumo do estoque e período de reposição do estoque" (FRANCISCHINI; GURGEL, 2010, p. 149). Nessa representação gráfica apresenta-se, conforme Pozo (2008), os níveis de estoques atuais da empresa, como o estoque mínimo, que significa a quantidade mínima de produtos que tem que existir no estoque, ainda em conformidade com Pozo (2008), com a função de cobrir as possíveis variações existentes.

Outro nível seria o ponto de reposição, que segundo Rubin (2016), no qual é o ponto em que é necessário realizar a compra de determinado material. Já o lote de compras, em concordância com Pozo (2008), é a quantidade de produtos especificados no pedido de compra, que está sujeito à política de estoque de cada empresa. O estoque de segurança, em harmonia com Rubin (2016), tem como finalidade compensar as incertezas inerentes ao fornecimento e demanda. Além desses níveis, há o tempo de reposição que, ainda em conformidade com Pozo (2008), é o tempo de solicitação da mercadoria e entrega e o último nível, é o estoque máximo, no qual normalmente é determinado de forma que seu volume ultrapasse a somatória da quantidade do estoque de segurança, com o lote de compra em um valor que dê para suportar as variações em face do mercado.

Outra técnica utilizada é a curva $\mathrm{ABC}$, conhecida como análise de Pareto ou regra 80/20, segundo Alves et al (2012), é um método de categorização de estoques cujo objetivo é determinar quais os produtos mais importantes de uma empresa. Em harmonia com Henrique (2010), a curva ABC recebeu esse nome em decorrência da metodologia utilizada, ou seja, do produto de maior importância para o de menor importância. 
Exemplo: A. Maior importância ou quantidade correspondente a $20 \%$.

B. Quantidade ou valor intermediário - correspondendo a 30\%

C. Menor importância - valor ou quantidade correspondendo a 50\%

De maneira abrangente, ainda em concordância com Henrique (2010), a curva ABC tem por funcionalidade mostrar qual produto tem maior lucratividade, ou seja, maior saída. Para aplicabilidade desse método, em concordância com Ferreira Filho et al (2016), é necessário que se faça uma análise geral de todos os produtos utilizados na empresa, podendo utilizar dois critérios para essa análise que são o giro de estoque e o de lucratividade. Tendo isso de maneira objetiva e clara, a empresa pode identificar por meio da aplicabilidade de uma tabela, a participação de cada item em sua receita total. Podendo, assim, gerenciar melhor seu estoque e direcionar as vendas de seu produto.

Outro sistema muito utilizado é o MRP, de acordo com o Vargas (2009), esse sistema surgiu na década de 60, quando houve uma onda de informatização das empresas, a necessidade de informatizar todos os processos. É um sistema de cálculo que automatiza desde o planejamento de materiais até sua produção, ou seja, ele analisa a necessidade de aquisição de novos produtos ou sua produção, considerando as informações de estoque de segurança de lote mínimo, máximo e múltiplo. Ainda de acordo com Vargas (2009), o sistema de cálculo combina com as demandas de um período com a política econômica da empresa, ou seja, ele analisa qual período é mais utilizado determinado produto, contribuindo assim com a redução de custos de estoques. Esse sistema traz maior confiabilidade e precisão nas informações de planejamento, evitando ações de emergência e atropelos no final do mês.

Outra metodologia utilizada é o sistema Just in Time, segundo Mendes e Ribeiro (2014), significa "na hora certa" no "tempo certo". É conhecido por, em concordância com Guarnieri e Hatakeyama (2010), uma filosofia de gestão para o planejamento e controle das operações com foco na qualidade e redução de desperdícios. Essa metodologia de acordo com Lima (2008), popularizou-se a partir da segunda metade do século XX, a montadora Toyota foi a pioneira no uso, que ficou conhecido também como Toyotismo. Outras empresas também aderiram ao sistema, como é o caso da Avon Cosméticos. Nesse sistema, de acordo com Guarnieri e Hatakeyama (2010), não existe estoque e a produção fica atrelada 
à solicitação do cliente, de maneira que só é adquirido o material para a produção de determinado produto e produzido apenas o que foi solicitado.

É um sistema que, em harmonia com Queiroz et al. (2016), evita desperdícios e estoques, porém, para que não haja qualquer risco é necessário que exista uma coordenação perfeita e próxima entre os fornecedores, além de um conhecimento preciso de seus consumidores, tendo em vista que a falta de produtos ou a má qualidade dos produtos entregues para a produção pode acarretar no comprometimento das vendas prejudicando, assim, a receita da empresa. E, de acordo com Lima (2008), esse tipo de sistema geralmente é indicado para setores cuja demanda seja estável ou que, pelo menos, seja possível prever de forma confiável as variações provocadas pela sazonalidade.

Quadro 1- Pesquisas realizadas sobre a temática

\section{Fonte}

Mesquita et al (2016)

Cintra (2015)

Rosa (2015)

\section{Objetivo}

A literatura apresentada pelo autor Mesquita et al (2016) tem por objetivo "avaliar qual o impacto da sazonalidade das vendas sobre o volume de estoques e sobre a rentabilidade das organizações que atuam no segmento industrial." (Mesquita et al, 2016).

Em concordância com a bibliografia de Cintra (2015) seu estudo objetiva-se em perscrutar o processo produtivo de uma empresa do setor calçadista de Franca, identificar os períodos de sazonalidade, avaliar os impactos que ela ocasiona sobre a produção e vendas e propor estratégias de produção para sua atuação eficiente ao longo destes períodos.

O objetivo da literatura de Rosa (2015) é averiguar a evolução da produção e consumo do mercado calçadista masculino de couro na região de Franca, SP, no qual investiga os principais fatores influentes, em especial, os períodos sazonais, para propor estratégias de gestão de negócios, permitindo que esse segmento atue de forma competitiva.

Fonte: Elaborado pelas autoras (2019). 
A sazonalidade, em harmonia com Mesquita et al. (2016), é uma qualidade que se verifica em uma estação. Um exemplo de sazonalidade seria durante o período de safra de tomate, no qual, ainda em concordância com Mesquita et al. (2016), a oferta é abundante e os preços baixos, acontecendo o adverso na entressafra, com oferta restrita e preços elevados. Com isso, é possível avaliar qual é o impacto da sazonalidade das vendas sobre o volume de estoque e sobre a rentabilidade da organização.

De acordo com Cintra (2015), a sazonalidade é um fenômeno que é caracterizado pela instabilidade entre oferta e demanda nos determinados períodos do ano, podendo ser anuais, mensais, semanais ou diários, sendo expressa em termos quantitativos. A sazonalidade sendo também referida como estacional, ainda em harmonia com Cintra (2015), é caracterizada por evento que não ocorre com frequência e ela resulta de causas naturais, econômicas, sociais e institucionais.

Já para Rosa (2015), a sazonalidade é uma situação que envolve um padrão específico para um período do ano, podendo se repetir em algumas épocas, sendo também referida como estacional. E, em referência aos negócios, em concordância com Rosa (2015), o termo sazonalidade é usado para falar sobre as vendas, onde há o período em que se venderá mais e o período em que venderá menos.

\section{MÉTODOS E TÉCNICAS}

Inicialmente, para a elaboração do estudo de caso, foi realizada uma pesquisa bibliográfica sobre gestão de estoque que se alinhasse com a necessidade do objeto de estudo. Após essas informações, foi desenvolvido um instrumento de pesquisa para coleta de dados do objeto de estudo para entendimento da atual política de estoques da empresa utilizada e se há necessidade de algum sistema de gerência do mesmo. 


\subsection{METODOLOGIA}

A metodologia deste trabalho tem como base o estudo de uma problemática e apresentação de uma possível solução, portanto, para iniciar a primeira etapa, será formulado um instrumento de pesquisa, para levantamento de dados, de caráter qualitativo aberto que será aplicado ao responsável pelo controle do estoque da empresa em estudo, por meio das metodologias dos autores Biazzi e Gianesi (2011) e Pozo (2008). A empresa foi escolhida devido a um dos autores atuar na área administrativa/financeira e ver a necessidade de organização em relação ao gerenciamento de materiais da organização.

O instrumento de pesquisa usado para obtenção de conhecimento foi um questionário aberto para levantamento de dados, que segundo Perrien (1986), tem como vantagem a característica de explorar todas as possíveis respostas a respeito de um item, servindo de base para a futura elaboração de um questionário fechado. Como regra geral, ainda em concordância com Perrien (1986), as questões iniciais abordem temas abertos, de fácil resposta, com o objetivo primordial de envolver o respondente, já as questões mais importantes e delicadas sejam inseridas no meio do questionário e as questões de caráter demográfico fiquem ao final.

Esse instrumento de pesquisa, tendo como fundamento os autores Biazzi e Gianesi (2011) e Pozo (2008), foi validado por três profissionais que atuam na área de gestão de materiais ou tenham conhecimento prévio sobre o tema em pauta, que abordará temas como: a) a importância de um bom gerenciamento de estoque; b) como isso pode afetar a imagem da empresa; c) métodos de estoque. Logo após, será realizado o referencial teórico para dar embasamento aos conhecimentos necessários.

Referente aos especialistas que autenticaram o instrumento de pesquisa, os três selecionados têm, no mínimo, escolaridade em ensino superior ou que tenham experiência sobre o tema em pauta comprovados, por meio de registro da CBO (Classificação Brasileira de Ocupações), sendo as validações de caráter online. O questionário para levantamento de dados será aplicado presencialmente e, para comprovação de validação, terá de ser encaminhado aos autores uma carta com seus dados pessoais e com os comentários sobre o instrumento de pesquisa.

Em continuidade com a pesquisa, após o resultado da avaliação do levantamento de dados, foi aplicado presencialmente ao responsável da gestão de estoque da empresa o 
questionário, com o intuito de obter conhecimento sobre o processo da gestão de estoques, que assim, sucederá a análise das informações obtidas.

O questionário para levantamento de dados foi aplicado presencialmente ao estagiário da organização, esse sendo um dos autores deste artigo, que faz o controle de materiais, entradas e saídas, entretanto não havendo uma visita in loco devido um dos autores atuarem dentro da organização. Ocorrendo uma análise prévia das listas de organização das movimentações do estoque e ao inventário de materiais, para entendimento e obtenção de resultados mais harmônicos, esses que serão anexados no artigo no tópico 3. Resultados e Discussões.

A seguir, apresenta-se como foi construído o questionário para levantamento de dados com base no referencial teórico:

1. O desempenho da administração de estoque afeta diretamente, segundo Biazzi e Gianesi (2011), nos objetivos estratégicos empresariais, esses ligados a estratégias competitivas como: a diferenciação ou liderança de custo. Apresentada essa relevância, qual a importância do estoque em uma empresa prestadora de serviços e comercializadora de produtos estéticos?

2. A função dos estoques, em harmonia com Biazzi e Gianesi (2011), decorre da necessidade de atender a um processo de demanda a partir de um processo de suprimento. "Os estoques são necessários na medida em que os processos de suprimento e demanda não podem ser sincronizados de forma a que as taxas de demanda e suprimento sejam idênticas em cada instante." (Biazzi e Gianesi, 2011). Com base nessa breve explicação, há conhecimento sobre se o processo de suprimento e a demanda do negócio têm sincronização entre eles?

3. "Em especial, dois objetivos afetam o estoque final desejado. Um deles está ligado ao atendimento da demanda, a qual, não podendo ser prevista com exatidão, requer que se planeje certo nível de estoque final, denominado de estoque de segurança, visando aumentar a probabilidade de atendimento da demanda futura. O outro está ligado ao custo necessário para se manterem estoques, fazendo com que se deseje o menor nível de estoques possível, visando reduzir esses custos." (Biazzi e Gianesi, 2011). Por que esses dois objetivos são conflitantes para o estoque final desejado?

4. De acordo com Biazzi e Gianesi, o desempenho da gestão dos estoques, notadamente em relação aos objetivos, afeta de forma direta o poder de competitividade da 
empresa. Explique como uma falha de gestão de estoque pode refletir na imagem da empresa.

5. A gestão dos estoques consiste em agir sobre o processo de suprimento - ou seja a manutenção do estoque depende do processo de demanda - sendo que esta manutenção se traduz pela decisão de o que suprir, em que quantidade e em que momento. Quais métodos utilizados para a previsão de demanda na empresa?

6. O modelo proposto para que se faça a gestão de estoques com visão estratégica é composto por quatro passos, em harmonia com Biazzi e Gianesi (2011). Quais são esses quatros passos? Exemplifique-os.

7. O nível de serviço determina os níveis de estoque (estoque máximo, estoque mínimo e estoque de segurança) que garantam a disponibilidade, em concordância com Biazzi e Gianesi (2011), mesmo sob altos níveis de incerteza sobre a demanda futura. Quanto maior o nível de serviço desejado, maior deverá ser o nível de armazenamento e, consequentemente, menor o giro. Já o giro de estoque, de acordo com Pozo (2008, p.47), releva a velocidades das vezes em que o entreposto foi renovado em determinado período ou qual é o tempo médio de permanência de uma mercadoria antes da venda. Com base nessas informações, como é determinado os níveis de estoques e se há conhecimento sobre o giro de estoque?

8. É necessário que se entenda qual a estratégia competitiva da empresa, bem como também sua estratégia de operações, isto é, de que forma os objetivos operacionais estão priorizados. Isso significa a empresa ter de forma clara e objetiva quais são os seus custos dos seus produtos, quem são seus fornecedores, prazos de entrega, confiabilidade. A empresa em questão tem esse gerenciamento de fornecedores?

9. A falta de um bom gerenciamento de estoque afeta diretamente a área de vendas e marketing da empresa, tendo em vista que essas áreas são primordiais para o bom funcionamento da mesma, ou seja, elas geram faturamento, portanto necessitam de um estoque "permanente". Por outro lado, as áreas financeira e controladoria priorizam um estoque mais enxuto, justificando que a manutenção de um estoque gera custos e que um capital empregado em um estoque poderia gerar dividendos se aplicados em outras operações. Tomando como base a explicação, quais os agravantes de uma falta de gerenciamento de estoques? 
REMIPE

10. Grande parte das empresas tanto nacionais quanto internacionais, segundo Biazi e Gianesi (2011), por falta de conhecimento ou até mesmo interesse, utilizava o método empírico de estoque, ou seja, baseado apenas em conhecimentos passados, sem qualquer estudo. Tendo como base o texto acima como é feito e qual é a metodologia que a empresa utiliza?

\section{RESULTADOS E DISCUSSÕES}

Com base nos resultados obtidos por meio do questionário para levantamento de dados aplicado à pesquisadora, que também é responsável administrativa pela área de compras e estoque da organização, percebe-se que a entrevistada desconhece os processos sobre a gestão de materiais. Com isso, direcionando a propor aos gestores da instituição um modelo de organização de mercadorias e a unificação da base de dados, ou seja, um novo layout, no qual irá possibilitar a visualização mais clara dos produtos existentes que há em estoque, tornando o controle de materiais mais eficiente.

O desempenho administrativo de estoque, de acordo com Biazzi e Gianesi (2011), afeta diretamente os objetivos estratégicos da organização, sendo que o desígnio da instituição estudada é o crescimento no mercado estético. Todavia, com a falta de gerenciamento do estoque, ocasiona a ausência de insumos para atendimento, causando insatisfação do cliente final e acarretando na má impressão da marca perante ao mercado, dificultando o crescimento almejado.

A importância de que a empresa adquira um conhecimento básico sobre a articulação da gestão de estoque para que se possa evidenciar, de maneira prática e funcional, os benefícios de se ter um bom gerenciamento é visível, pois em harmonia com Costenaro, Cassel e Oliveira (2016), a gerência de materiais passou a ser uma das mais importantes operações de indústrias e comércios, agenciando grande impacto no desempenho global das companhias. Observa-se que para a realização desse objetivo, não é necessário ter um estoque volumoso, nem tão pouco crítico, mas sim níveis de estoque adequados em harmonia com a demanda da organização, considerando a sazonalidade existente na operação. 


\section{CONSIDERAÇÕES FINAIS}

O objetivo do estudo é demonstrar que, a partir da melhor gestão de materiais, por meio de ferramentas, o quão a administração correta pode impactar no custo de estoque da empresa, fazendo que não haja falta de produtos, as quais prejudicam os atendimentos e causando má impressão da marca. Com base na problemática relatada, foi gerada a seguinte pergunta norteadora: como uma melhor gestão de materiais poderá reduzir a falta de mercadorias e impactar nos custos referentes ao estoque na empresa pesquisada?

Após estudos e levantamento de dados obtidos por meio do questionário, foi constatado que o responsável pelo estoque da empresa desconhece os processos sobre a gestão de materiais e a sua importância. No qual foi sugerida para resolução da problemática, a realização de alterações no layout e a unificação da base de dados, pois dessa forma a visualização do que há no acervo ficaria mais clara e com isso auxiliaria a definir os níveis de materiais. Além de que com a melhor visualização dos produtos, o rearranjo físico poderá contribuir na redução das decorrentes faltas de insumos para atendimento aos clientes, com base na fundamentação teórica, levando a problemática do objeto estudado à solução e, para estudos posteriores, fica em aberto a necessidade de organização dos níveis de estoques, o seu giro e identificação da demanda, considerando a sazonalidade como um fator impactante.

\section{REFERÊNCIAS}

ALVES, Ana Paula Ferreira et al. Custos de suprimentos: estudo exploratório com aplicação de modelo de mensuração de custos logísticos, 2012. Disponível em: encurtador.com.br/nxHIW> acesso em 16 de junho de 2019, às 18h42min.

ARAÚJO, Valdineide dos Santos; MACHADO, Márcio André Veras. Gestão do giro de capital de pequenas empresas, 2007. Fortaleza: Revista Ciências Administrativas, 2007.

BIAZZI, Jorge Luiz de; GIANESI, Irineu Gustavo Nogueira. Gestão Estratégica dos Estoques, 2011. Disponível em: <encurtador.com.br/fwCNU> acesso em 27 de abril de 2019, às $14 \mathrm{~h} 27 \mathrm{~min}$.

REMIPE- Revista de Micro e Pequenas Empresas e Empreendedorismo da Fatec Osasco

V. $6 \mathrm{~N}^{\circ} 1$ jan.-jun. 2020. 
CINTRA, Tales Luvizoto. Estratégias de produção para uma indústria calçadista em períodos sazonais, 2015. Disponível em: <encurtador.com.br/HJOU9> acesso em 15 de setembro de 2019, às 20h58min.

COSTENARO, Suellen Sonego; CASSEL, Ricardo Augusto; e OLIVEIRA, Luciano Valente de. Gestão estratégica de materiais - o caso de um hospital beneficente, 2016. Disponível em: <encurtador.com.br/gpyQ2> acesso em 25 de maio de 2019, às 21h09min.

DINO. Mercado de estética e beleza no Brasil segue em crescimento, 2019. Disponível em: <encurtador.com.br/duLNO > acesso em 26 de maio de 2019, às 14h35min.

DINO. Segundo informações, mercado de estética segue em expansão, 2018. Disponível em: <encurtador.com.br/kqruC > acesso em 26 de maio de 2019, às 16h08min.

FERREIRA FILHO, José Arthur et al. Análise de perdas de produtos a luz da gestão de estoque um estudo de caso numa empresa distribuidora de bebidas cearense, 2016. Disponível em: < encurtador.com.br/foPR5> acesso em 16 de junho de 2019, às 18h49min.

FRANCISCHINI, Paulino G.; GURGLE, Floriano do Amaral. Administração de Materiais e do Patrimônio. 2. ed. São Paulo: Cengage Learning Edições LTDA., 2010.

GITMAN, Lawrence J. Princípios de administração financeira, 1997. São Paulo: Harbra, 1997.

GUARNIERI, Patrícia; HATAKEYAMA, Kazuo. Formalização da logística de suprimentos: caso das montadoras e fornecedores da indústria automotiva brasileira, 2010. Disponível em: < encurtador.com.br/fBOQX> acesso em 16 de junho de 2019, às $18 \mathrm{~h} 29 \mathrm{~min}$.

HENRIQUE, Claudio. Sobre Administração: Curva ABC, Análise de Pareto - o que é e como funciona, 2010. Disponível em <encurtador.com.br/bfMT0> acesso em 26de maio de 2019, as 21h40min.

LIMA, M. O que é Just in time? - Modelo de Gestão adotado pelo Japão que faz sucesso em todo o mundo, 2008. Disponível em <encurtador.com.br/bdeE1> acesso em 26 de maio $23 \mathrm{~h} 30 \mathrm{~min}$. 
REMIPE

MENDES, Angélica Alebrant; RIBEIRO, José Luis Duarte. Estabelecimento de um plano de manutenção baseado em análises quantitativas no contexto da MCC em um cenário de produção JIT, 2014. Disponível em: < encurtador.com.br/djkC4> aceso em 16 de junho de 2019, às 18h20min.

MESQUITA, José Marcos de Carvalho et al. Impactos da sazonalidade da produção sobre os estoques e lucratividade: análise do segmento industrial brasileiro, 2016. Disponível em: <encurtador.com.br/vwRT7> acesso em 15 de setembro de 2019, às 19h55min.

PERRIEN, Jean. Recherche en Marketing: méthodes et décisions. Canada: Gaetan Morin, 1986.

PITTA, Sandra. Mercado de estética e beleza no Brasil segue em crescimento, Casa Miracolli, 2019. Disponível em: <encurtador.com.br/duIS8> acesso em 26 de maio de 2019, às $19 \mathrm{~h} 51 \mathrm{~min}$.

POZO, Hamilton. Administração de Recursos Materiais e Patrimoniais: Uma Abordagem Logística. 5. ed. São Paulo: Atlas, 2008.

QUEIROZ, Romeiro Alves et al. A TOC na prática: explorando a restrição em uma fábrica, 2016. Disponível em: <encurtador.com.br/iFS04> acesso em 16de junho de 2019, às $18 \mathrm{~h} 3 \mathrm{~min}$.

ROSA, Carlos Augusto de Melo. Estratégias competitivas para enfrentar a sazonalidade na indústria de calçados de Franca-SP, 2015. Disponível em: <encurtador.com.br/nrBQ9> acesso em 15 de setembro de 2019, às 21h19min.

RUBIN, Lucas Librelotto. Gerenciamento de estoques: aplicação do modelo de lote econômico de compra em uma empresa do setor metal mecânico, 2016. Disponível em: <encurtador.com.br/dwyF4> acesso em 25 de maio de 2019, às 21h49min.

SANTOS, Antônio Marcos dos; RODRIGUES, Iana Araújo. Controle de estoque de materiais com diferentes padrões de demanda: estudo de caso em uma indústria química, 2006. Disponível em: <encurtador.com.br/gjqSV> acesso em 25 de maio de 2019, às $20 \mathrm{~h} 44 \mathrm{~min}$. 
REMIPE

\ҐFatec

VARGAS, Rodrigo. Gestão Industrial.com -MRP - Manufacturing _Resources_Planning- Planejando Materiais e programando produção através do sistema, 2009. Disponível em: <encurtador.com.br/bIV24> acesso em 27de maio de 2019 01h10min.

REMIPE- Revista de Micro e Pequenas Empresas e Empreendedorismo da Fatec Osasco V. $6 \mathrm{~N}^{\circ} 1$ jan.-jun. 2020. 